\title{
Medidas morfométricas do rebanho atual de fêmeas Mangalarga Marchador e das campeãs da raça
}

\author{
Morphometric measurements of current herd Mangalarga Marchador females and \\ champions of breed
}
SANTIAGO, Juliano Martins ${ }^{1 *}$; REZENDE, Adalgiza Souza Carneiro de ${ }^{1}$; LANA, Ângela Maria Quintão ${ }^{1}$; FONSECA, Mayara Gonçalves ${ }^{1}$; ABRANTES, Renata Guimarães Pequeno ${ }^{1}$; LAGE, Jéssica ${ }^{1}$; ANDRADE, Juliana Moreira ${ }^{1}$; RESENDE, Thiago Magalhães ${ }^{1}$

\author{
${ }^{1}$ Universidade Federal de Minas Gerais, Escola de Veterinária, Departamento de Zootecnia, Belo \\ Horizonte, Minas Gerais, Brasil. \\ *Endereço para correspondência: jmartinssantiago@yahoo.com.br
}

\section{RESUMO}

Objetivou-se comparar as medidas morfométricas do rebanho atual de fêmeas Mangalarga Marchador (MM) com os exemplares campeões. $\mathrm{O}$ delineamento experimental foi inteiramente ao acaso, sendo os tratamentos constituídos pelo rebanho atual de fềmeas da raça MM, representado por todas as éguas registradas entre 2000 e 2012 que tiveram suas medidas armazenadas no banco de dados do Serviço de Registro Genealógico da Associação Brasileira de Criadores do Cavalo Mangalarga Marchador, totalizando 51993 animais; e pelas campeãs da raça, representadas por 266 animais campeões. Foram avaliadas a altura na cernelha e na garupa, comprimento da cabeça, pescoço, espádua, dorso-lombo, garupa e corpo, largura da cabeça e da garupa e perímetro torácico e da canela. As medidas lineares foram relacionadas ao comprimento da cabeça, de acordo com o Sistema Eclético de Proporções. Os resultados das 12 medidas lineares foram submetidos à análise de variância e as médias comparadas pelo teste de Fisher $(p<0,05)$. Em relação ao rebanho atual de fêmeas $\mathrm{MM}$, as éguas campeãs da raça apresentaram maior comprimento da cabeça, corpo, pescoço, dorso-lombo e garupa, altura na cernelha e na garupa, largura da garupa e perímetro torácico e da canela. Concluiu-se que embora apresentem maiores medidas lineares, as éguas campeãs $\mathrm{MM}$ são proporcionalmente semelhantes ao rebanho atual de fềmeas da raça.

Palavras-chave: equino, marcha, proporção, seleção

\section{SUMMARY}

The study aimed to compare the morphometric measures of the current herd Mangalarga Marchador (MM) female with champions breed, using as parameters the breed standard and the Eclectic System of Proportions for saddle horse. The experimental design was randomized, and the treatments were the current herd $\mathrm{MM}$ female, represented by all mares registered between 2000 and 2012 that had your measurements stored in the database service studbook of breed, totaling 51993 animals, and the champions breed, represented by 266 mares champions. Were evaluated measures of height at withers and at rump, length of the head, neck, dorse, rump, shoulder and body, width of head and of rump, thoracic perimeter and cannon perimeter. The mean linear measurements were related to the length of the head, according to Eclectic System of Proportions. The results were submitted to analysis of variance and the means were compared by Fisher's test $(p<0.05)$. Regarding the current herd of females MM, the champions breed showed greater length of the head, body, neck, dorse and rump, height at withers and at rump, width of rump and thoracic and cannon perimeter. It was concluded that although larger, the champions Mangalarga Marchador mares are proportionally similar to the current herd.

Keywords: equine, marcha, proportion, selection 


\section{INTRODUÇÃO}

A raça nacional Mangalarga Marchador surgiu há cerca de 200 anos no Sul de Minas Gerais, através do cruzamento de um garanhão Alter com éguas nativas (CASIUCH, 1997). Atualmente é a mais numerosa raça nacional de equinos, tendo sido objeto de atenção, tanto por sua beleza zootécnica e andamento marchado, quanto por seu desempenho na agropecuária. A versatilidade dos equinos Mangalarga Marchador, aliada a sua conformação e andamento marchado, são características que levam os animais a atingirem elevados preços no mercado.

Estudos sobre "forma prediz função" têm demonstrado que muitas das características físicas são instrumentos importantes na determinação de como um cavalo se move e atua. Portanto, a morfologia é fundamental para a execução e qualidade dos movimentos, interrelacionando-se com a aptidão do animal (JONES, 1987). De acordo com Zamborlini \& Pereira (1996), tradicionalmente a avaliação morfológica do equino é realizada de modo subjetivo, onde criadores, técnicos e juízes baseiam em informações obtidas do exterior dos animais, sem contar com nenhum tipo de critério científico. Porém, características de conformação dos equinos que podem ser avaliadas de forma objetiva, através de mensurações hipométricas e barimétricas, constituem informações importantes no estabelecimento da seleção das raças equinas (FARIA et al., 2004).

Segundo Bergmann et al. (1997), existem evidências de que características importantes das raças equinas nacionais estejam se alterando com o passar das gerações. Nos últimos anos a raça Mangalarga Marchador tem evoluído, praticando atividades mais atléticas e adequando-se ao tipo sela internacional.
Esta evolução pode ser percebida nas exposições especializadas da raça, onde os criadores comparam seu rebanho com os campeões da raça, adotando-os como parâmetro zootécnico (COSTA et al., 2006). Neste contexto, o presente estudo objetivou verificar a evolução das características morfológicas da raça Mangalarga Marchador, comparando as medidas morfométricas do atual rebanho de equinos fêmeas com as campeãs da raça, utilizando como parâmetros o padrão racial e o Sistema Eclético de Proporções para cavalo de sela.

\section{MATERIAL E MÉTODOS}

A etapa experimental foi desenvolvida no Parque de Exposições Bolivar de Andrade, Belo Horizonte - MG e o processamento dos dados realizado na Escola de Veterinária da Universidade Federal de Minas Gerais (UFMG). Este estudo foi aprovado pelo Comitê de Ética em Experimentação Animal da UFMG, sob o protocolo ${ }^{\circ}$ 152/2011. Para representar o rebanho atual de equinos fêmeas da raça Mangalarga Marchador, foram avaliadas 12 medidas lineares de todos as fêmeas registradas entre 2000 e 2012 que tiveram suas medidas armazenadas no banco de dados do Serviço de Registro Genealógico da Associação Brasileira de Criadores do Cavalo Mangalarga Marchador (ABCCMM), totalizando 51993 animais. Para representar os exemplares campeões da raça, foram mensuradas 12 medidas lineares de 266 éguas, todas credenciadas anualmente com os títulos de campeã ou reservada campeã nas exposições regionais oficializadas pela ABCCMM em todo o Brasil e detentoras dos títulos de campeã, reservada campeã, $1^{\circ}, 2^{\circ}, 3^{\circ}, 4^{\circ}$ ou $5^{\circ}$ prêmio das categorias convencionais de marcha 
batida e picada, acima de cinco anos, na $29^{\mathrm{a}}, 30^{\mathrm{a}}$ ou $31^{\mathrm{a}}$ Exposição Nacional do Cavalo Mangalarga Marchador, realizadas em 2010, 2011 e 2012, respectivamente. O delineamento experimental foi inteiramente ao acaso, sendo os tratamentos constituídos pelas medidas lineares do rebanho atual de fêmeas da raça Mangalarga Marchador e das éguas campeãs.

As mensurações foram realizadas com os animais em estação forçada e sempre do lado esquerdo do animal, seguindo a metodologia utilizada pelos técnicos de registro da ABCCMM. Os equipamentos utilizados nas mensurações foram um hipômetro e duas fitas métricas. $\mathrm{O}$ hipômetro consiste em uma haste e dois braços de metal, sendo a haste uma régua, graduada em centímetros e um dos braços um ramo horizontal que pode ser movido ao longo da haste para as medidas de altura. O outro braço é acoplado à haste para mensuração das medidas de largura e comprimento. Uma fita métrica medindo 2 metros, com precisão de $0,1 \mathrm{~cm}$, foi utilizada para mensuração do perímetro torácico e a outra, com precisão de $0,01 \mathrm{~cm}$, foi utilizada para mensuração do perímetro da canela do membro anterior.

Foram determinadas as medidas de altura na cernelha e na garupa, perímetro torácico e da canela, comprimento da cabeça, pescoço, dorso-lombo, garupa, espádua e corpo e largura da cabeça e da garupa, segundo Zamborlini et al. (1996), Lage et al. (2009) e Gonçalves et al. (2012):

As médias das 12 medidas obtidas em cada período foram comparadas com o Sistema Eclético de Proporções para cavalos de sela (LESBRE, 1930), o qual determina que as medidas lineares sejam relacionadas ao comprimento da cabeça. Os resultados foram submetidos à análise de variância e as médias comparadas pelo teste de Fisher $(\mathrm{p}<0,05)$, utilizando o software SAEG versão 9.1 (UFV, 2007).

\section{RESULTADOS E DISCUSSÃO}

Houve diferença $(p<0,05)$ entre $o$ rebanho atual de fêmeas Mangalarga Marchador e as campeãs da raça em 10 das 12 medidas avaliadas (Tabela 1).

As éguas campeãs apresentaram comprimento da cabeça $1,4 \mathrm{~cm}$ superior ao do rebanho atual de fêmeas, 57,6 e $56,2 \mathrm{~cm}$, respectivamente. Já a largura da cabeça e a proporção entre $o$ comprimento e a largura da cabeça foram semelhantes entre as duas categorias, embora pouco acima da proporção preconizada para o cavalo de sela, de 1:0,33 (LESBRE, 1930), indicando que, proporcionalmente, as fêmeas Mangalarga Marchador têm uma fronte mais larga que a relação proposta para o cavalo de sela.

Barbosa (1993) comparou as medidas morfométricas de égua campeãs e não campeãs da raça Mangalarga Marchador e não observou diferença no comprimento da cabeça entre as duas categorias, registrando média de 57,0cm. Já Zamborlini et al. (1996) e Gonçalves et al. (2012), que também avaliaram fêmeas Mangalarga Marchador, registraram valores próximos ao observado nas éguas campeãs, 57,6cm. Segundo Gonçalves et al. (2012), o comprimento e a largura da cabeça dos equinos são medidas importantes por conferirem expressão racial. Nas raças brasileiras de marcha, a cabeça curta, desde que equilibrada, constitui qualidade e beleza zootécnica, ainda mais quando ligada a um pescoço longo, pois é fácil de ser conduzida, além de aliviar os membros torácicos (NASCIMENTO, 1999). 
Rev. Bras. Saúde Prod. Anim., Salvador, v.15, n.1, p.141-148 jan./mar., 2014 http://www.rbspa.ufba.br ISSN 15199940

Tabela 1. Médias das medidas lineares de equinos fêmeas mensuradas entre 2000 e 2012 (rebanho atual) e das campeãs da raça, com os respectivos coeficientes de variação $(\mathrm{CV})$ e as proporções entre estas medidas e o comprimento da cabeça

\begin{tabular}{lcccccc}
\hline Medidas (cm) & $\begin{array}{c}\text { Rebanho } \\
\text { atual }\end{array}$ & Proporção & $\begin{array}{c}\text { Campeãs } \\
\text { da raça }\end{array}$ & Proporção & $\begin{array}{c}\text { Proporção } \\
(\text { Lesbre, 1930) }\end{array}$ & $\begin{array}{c}\text { CV } \\
(\%)\end{array}$ \\
\hline Comp. cabeça & $56,2^{\mathrm{b}}$ & - & $57,6^{\mathrm{a}}$ & - & - & 3,2 \\
Largura cabeça & 19,8 & 0,35 & 19,8 & 0,34 & 0,33 & 6,8 \\
Altura cernelha & $146,0^{\mathrm{b}}$ & 2,60 & $150,0^{\mathrm{a}}$ & 2,60 & 2,50 & 2,2 \\
Altura garupa & $145,0^{\mathrm{b}}$ & 2,58 & $149,0^{\mathrm{a}}$ & 2,59 & 2,50 & 3,2 \\
Comp. corpo & $149,0^{\mathrm{b}}$ & 2,65 & $155,0^{\mathrm{a}}$ & 2,69 & 2,50 & 2,6 \\
Comp. pescoço & $61,1^{\mathrm{b}}$ & 1,09 & $65,9^{\mathrm{a}}$ & 1,14 & 1,00 & 4,4 \\
Comp. espádua & 51,0 & 0,91 & 50,8 & 0,88 & 1,00 & 3,9 \\
Comp. dorsolombo & $48,6^{\mathrm{b}}$ & 0,86 & $51,1^{\mathrm{a}}$ & 0,89 & 0,83 & 6,9 \\
Comp. garupa & $50,5^{\mathrm{b}}$ & 0,90 & $55,5^{\mathrm{a}}$ & 0,96 & 0,83 & 5,1 \\
Largura garupa & $49,6^{\mathrm{b}}$ & 0,88 & $52,9^{\mathrm{a}}$ & 0,92 & 0,83 & 4,2 \\
Perímetro torácico & $171,0^{\mathrm{b}}$ & - & $178,0^{\mathrm{a}}$ & - & - & 3,0 \\
Perímetro canela & $17,7^{\mathrm{b}}$ & - & $18,8^{\mathrm{a}}$ & - & - & 3,7 \\
\hline Letras distintas nas linhas diferem entre o rebanho atual e as campeãs da raça pelo teste de Fisher $(\mathrm{p}<0,05)$.
\end{tabular}

Tanto a altura na cernelha quanto a altura na garupa das fêmeas campeãs foram $4,0 \mathrm{~cm}$ maior a média do rebanho. Porém, quando as alturas na cernelha e na garupa foram relacionadas ao comprimento da cabeça, as proporções observadas foram semelhantes, indicando, que embora maiores, as éguas campeãs são proporcionalmente semelhantes ao rebanho atual de fêmeas da raça.

Deve-se considerar que as medidas arquivadas no banco de dados do Serviço de Registro Genealógico da ABCCMM foram feitas, na sua maioria, em animais ainda em crescimento, pois o registro definitivo é feito a partir dos três anos e os equinos completam seu desenvolvimento corporal aos cinco anos de idade (NASCIMENTO, 1999). Portanto, é possível que a altura na cernelha observada no rebanho atual de fêmeas Mangalarga Marchador esteja subestimada.
O padrão racial do Mangalarga Marchador preconiza como altura na cernelha ideal para as fêmeas de $146,0 \mathrm{~cm}$, admitindo-se para o registro definitivo altura mínima de $140,0 \mathrm{~cm}$ e máxima de $154,0 \mathrm{~cm}$. Assim, nas fềmeas campeãs e participantes das três exposições nacionais, a altura na cernelha ultrapassou em $4,0 \mathrm{~cm}$ a altura ideal estabelecida pelo padrão da raça. Apesar das alturas na cernelha e na garupa das éguas campeãs serem maiores, em relação ao rebanho atual, a diferença entre estas duas medidas em ambas as categorias foi a mesma, $1,0 \mathrm{~cm}$. A manutenção desta diferença de $1,0 \mathrm{~cm}$ provavelmente deve-se a seleção realizada pelos criadores e técnicos, procurando atender ao padrão racial que desclassifica as fêmeas que apresentarem altura na garupa superior a altura na cernelha em $2 \mathrm{~cm}$ ou mais. Segundo Cid (1999), altura na garupa superior a altura na cernelha é considerada desclassificante por estar 
associada a angulações inadequadas dos membros anteriores e/ou posteriores, que desta forma se tornam prejudiciais aos andamentos e à resistência do equino (CID, 1999).

O comprimento do corpo das éguas campeãs foi $6,0 \mathrm{~cm}$ maior que a média do rebanho, 155,0 e $149,0 \mathrm{~cm}$ respectivamente. No sistema eclético de Proporções para cavalo de sela, além da relação entre as medidas corporais e o comprimento da cabeça, outras proporções foram estabelecidas, como a relação entre a altura na cernelha e o comprimento do corpo, que deve ser de 1:1 (LESBRE, 1930). No presente estudo a relação entre altura na cernelha e comprimento do corpo do rebanho de fêmeas da raça foi de 1,02 e das éguas campeãs de 1,03 . Portanto, mais uma vez constatou-se que embora maiores, as éguas campeãs são proporcionalmente semelhantes ao rebanho atual de fêmeas da raça.

O comprimento do pescoço das fêmeas campeãs foi $4,8 \mathrm{~cm}$ maior que a média do rebanho, 65,9 e $61,1 \mathrm{~cm}$, respectivamente. Barbosa (1993), Zamborlini et al. (1996) e Pinto (2007) relataram comprimento do pescoço de fêmeas Mangalarga Marchador mais próximo de $61,1 \mathrm{~cm}$. O maior comprimento do pescoço das fêmeas campeãs distanciou a proporção entre esta medida e o comprimento da cabeça. Quando essa proporção foi comparada com a preconizada para o cavalo de sela (LESBRE, 1930), verificou-se aumento de 9 e 12\% para o rebanho de fêmeas e as éguas campeãs, respectivamente.

A mensuração aos três anos de idade pode ter contribuído para $\mathrm{o}$ menor comprimento do pescoço, e provavelmente aos cinco anos as fêmeas do rebanho atual apresentarão pescoço mais comprido, pois segundo Meyer (1995) nos equinos os ossos longos podem se desenvolver até os três anos de idade, quando ocorre a calcificação dos discos epifisários, mas nos ossos curtos e chatos, como as vértebras cervicais, a calcificação das cartilagens epifisárias ocorre mais tarde, entre três e cinco anos.

Não houve diferença $(\mathrm{P}>0,05)$ entre o comprimento da espádua do rebanho de fềmeas e das éguas campeãs, 51,0 e $50,8 \mathrm{~cm}$, respectivamente, e as proporções entre esta medida e o comprimento da cabeça foram muito próximas. No entanto, em ambas as categorias, a proporção entre o comprimento da cabeça e o da espádua foi menor que a relação proposta para o cavalo de sela, de 1:1 (LESBRE, 1930).

O comprimento e a angulação da espádua são medidas importantes na qualidade de movimentação dos equinos, pois estão associados à amplitude da passada e ao amortecimento do impacto do membro no solo, relacionando-se diretamente com a comodidade e rendimento do andamento (LAGE et al., 2009). Reforçando este fato, Barbosa (1993), Zamborlini et al. (1996), Pinto (2007), Lage et al. (2009) e Gonçalves et al. (2012) observaram comprimento da espádua superior ao das éguas campeãs do presente estudo, 53,2, 52,0, 60,0, 54,6 e $52,39 \mathrm{~cm}$, respectivamente. Assim, esperava-se maior comprimento da espádua das éguas campeãs mensuradas no presente estudo, pois além da importância desta região zootécnica na função desempenhada pelos animais, as fêmeas campeãs apresentaram valores superiores ao do rebanho atual em 10 das 12 medidas avaliadas.

O comprimento do dorso-lombo das éguas campeãs foi $2,5 \mathrm{~cm}$ maior que a média do rebanho, apresentando maior proporção em relação ao comprimento da cabeça $(0,89: 1)$, quando comparada ao rebanho atual $(0,86: 1)$ e a proporção preconizada por Lesbre (1930) para o cavalo de sela $(0,83: 1)$. Dorso-lombo 
mais comprido também foi registrado por Barbosa (1993) nas éguas campeãs, em relação às fêmeas não campeãs. Considerando somente o comprimento do dorso-lombo das éguas campeãs e participantes das exposições nacionais, $51,1 \mathrm{~cm}$, este valor foi semelhante ao observado por Pinto (2007), e inferior as medidas apresentadas por Barbosa (1993), Zamborlini et al. (1996) e Gonçalves et al. (2012) de 53,4; 55,0 e $52,2 \mathrm{~cm}$, respectivamente.

As éguas campeãs também apresentaram comprimento e largura da garupa superior a média do rebanho, com diferenças de 5,5 e $3,3 \mathrm{~cm}$, respectivamente. Os maiores valores destas medidas nas éguas campeãs distanciaram da proporção de 0,83:1, preconizada para o cavalo de sela (LESBRE, 1930). Avaliando a proporção entre comprimento e largura da garupa observa-se que no rebanho atual essa relação está muito próxima da recomendada para o cavalo de sela, de 1:1 (CID, 1999), mas as fêmeas campeãs mostram uma garupa com largura $2,6 \mathrm{~cm}$ menor que o comprimento, o que pode ser prejudicial, pois predispõem a partos distócicos, devido ao menor diâmetro do canal do parto.

O perímetro torácico das éguas campeãs foi $7,0 \mathrm{~cm}$ maior que a média do rebanho de fêmeas da raça. Valores próximos a $178,0 \mathrm{~cm}$, referente as éguas campeãs, foram observados por Barbosa (1993), Lage et al. (2009) e Pinto (2007) de $176,0,177,0$ e $179,6 \mathrm{~cm}$, respectivamente. Já Zamborlini et al. (1996) e Gonçalves et al. (2012) observaram menores valores, 172,0 e $170,0 \mathrm{~cm}$, respectivamente.

A raça Mangalarga Marchador é muito utilizada em diversas atividades funcionais (cavalgadas em longas distâncias, enduros, provas funcionais e concursos de marcha) e, para desempenho satisfatório, bom desenvolvimento torácico é fundamental (REZENDE et al., 2000). Para que alcancem bom rendimento na atividade desempenhada, os equinos deverão ter caixa torácica profunda, com costelas largas e bem arqueadas. Pois esta região, além de proporcionar base para inserção dos músculos das extremidades anteriores, aloja e serve de proteção para órgãos vitais (REZENDE et al., 2000). Portanto, perímetro torácico de $178,0 \mathrm{~cm}$, apresentado pelas éguas campeãs, além de ser condizente com as demais medidas avaliadas que foram, na grande maioria, superiores às do rebanho atual de fêmeas da raça, é adequado às funções desempenhadas pela raça.

O perímetro da canela das éguas campeãs foi $1,1 \mathrm{~cm}$ maior que a média do rebanho. Além do maior desenvolvimento corporal das éguas campeãs, a adoção de melhores práticas nutricionais no manejo dos animais de elite, especialmente quanto às exigências nutricionais e relações entre os principais minerais presentes na dieta, podem estar relacionados à diferença observada.

Concluiu-se que embora apresentem maiores medidas lineares, as éguas campeãs Mangalarga Marchador são proporcionalmente semelhantes ao rebanho atual de fêmeas da raça. Maiores medidas morfométricas observadas nas fêmeas campeãs da raça sinalizam que os equinos Mangalarga Marchador tendem a apresentar maior comprimento das diferentes regiões zootécnicas, uma vez que os campões da raça são utilizados como parâmetros de seleção dentro dos criatórios.

\section{AGRADECIMENTOS}

À Associação Brasileira dos Criadores do Cavalo Mangalarga Marchador. 
Rev. Bras. Saúde Prod. Anim., Salvador, v.15, n.1, p.141-148 jan./mar., 2014 http://www.rbspa.ufba.br ISSN 15199940

\section{REFERÊNCIAS}

BARBOSA, C.G. Estudo morfométrico na raça Mangalarga Marchador: uma abordagem multivariada. $1993.77 \mathrm{p}$.

Dissertação (Mestrado em Zootecnia) Universidade Federal de Minas Gerais, Belo Horizonte.

BERGMANN, J.A.G.; COSTA, M.D.; MOURÃO, G.B. Inbreeding effects on morphological traits of Brasileira pony breed. Arquivo Brasileiro de Medicina Veterinária e Zootecnia, v.49, p.103-111, 1997.

CASIUCH, R. O romance da raça: histórias do cavalo Mangalarga Marchador. São Paulo: Empresa das Artes, 1997. 254p.

CID, P.S. Hipologia. O Exterior do Cavalo. Lisboa: MG editores, 1999. $116 p$.

COSTA, H.G.; COSTA, J.A.B.; CAIADO, J.R.C. Evaluation of Equine "Mangalarga Marchador": a Multicriteria Analysis by ELECTRE II Method. Revista Pesquisa e Desenvolvimento Engenharia de Produção, n.5, p.1-17, 2006.

FARIA, R.; SILVA, M.A.; BUENO, R.S.; TORRES, R.A.; LOPES, P.S.; EUCLYDES, R.F.; PEREIRA, J.C.C.; BERGMANN, J.A.G.; FRIDRICH, A.B.; FERREIRA, I.C. Genetic and phenotipic evaluation of conformational traits in foals of equine of three breeds.

Revista Ceres, v.51, n.295, p.333-344, 2004.

GONÇALVES, R.W.; COSTA, M.D.; REZENDE, A.S.C. ROCHA JÚNIOR, V.R.; LEITE, J.R.A. Effect of inbreeding on morfhometric traits in Mangalarga Marchador horses.
Arquivo Brasileiro de Medicina Veterinária e Zootecnia, v.64, n.2, p.419-426, 2012.

JONES, W.E. Genética e criação de cavalos. São Paulo: Roca, 1987. 666p.

LAGE, M.C.G.R.; BERGMANN, J.A.G.; PROCÓPIO, A.M.; PEREIRA, J.C.C.; BIONDINI, J. Phenotypic association between linear and joint angle traits of Mangalarga Marchador horses. Arquivo Brasileiro de Medicina Veterinária e Zootecnia, v.61, n.4, p.968-979, 2009.

LESBRE, F.X. Precis d'Exterieur du Cheval. Paris: Vigot Fréres. 1930.

MEYER, H. Alimentação de cavalos. São Paulo: Varela, 1995. 303p.

NASCIMENTO, J.F. Mangalarga marchador: tratado morfofuncional. Belo Horizonte: Abccmangalarga Marchador, 1999. 577p.

PINTO, B.P. Avaliação morfométrica de éguas da raça Mangalarga Marchador. 2007. 42p. Monografia (Conclusão do curso de Medicina Veterinária) - Faculdade de Medicina Veterinária, Pontifícia Universidade Católica de Minas Gerais Betim.

REZENDE, A.S.C.; SAMPAIO, I.B.M.; LEGORRETA, G.L.; MOREIRA, D.C.A. Effect of Two Different Nutritional Programs on Development in Mangalarga Marchador Foals.

Revista Brasileira de Zootecnia, v.29, n.2, p.495-501, 2000.

UVIVERSIDADE FEDEWRAL DE VIÇOSA - UFV. SAEG- Sistemas para análise estatística e genética. Versão 9.1. Viçosa, 2007. 150p. 
Rev. Bras. Saúde Prod. Anim., Salvador, v.15, n.1, p.141-148 jan./mar., 2014 http://www.rbspa.ufba.br ISSN 15199940

ZAMBORLINI, L.C.; BERGMANN, J.A.G.; PEREIRA, C.S. Estudo

genético-quantitativo de medidas lineares de equinos da raça Mangalarga Marchador - I. Estimativas dos fatores de ambiente e parâmetros genéticos. Revista Brasileira de Ciências Veterinárias, v.3, n.2, p.33-37, 1996a.

ZAMBORLINI, L.C.; PEREIRA, J.C.C. Melhoramento genético aplicado aos equinos. In: PEREIRA, J.C.C. (Ed.)

Melhoramento genético aplicado à produção animal. Belo Horizonte: FEPMVZ, 1996b. p.313-324.

Data de recebimento: $15 / 05 / 2013$

Data de aprovação: 25/02/2014 